Journal of Mathematics and Statistics 4 (2): 108-111, 2008

ISSN 1549-3644

(C) 2008 Science Publications

\title{
The Estimation of Logistic Probability Model of Binomial Data: Simulation Comparison
}

\author{
Zaki. J. Al- Sarraf, Faris M. Al- Athari and Hilmi F. Kittani \\ Department of Mathematics, Hashemite University, P.O. Box 150459, \\ Zarqa 13115, Jordan
}

\begin{abstract}
Properties of various types of estimators of the regression coefficients in linear logistic regression models were considered. The estimators include those based on maximum likelihood, minimum chi-square and weighted least squares. The results of a large scale simulation investigation evaluating the moment properties of the estimators are presented for the case of logistic model with a single explanatory variable.
\end{abstract}

Keywords: Maximum likelihood, newton- raphson approach, weighted least squares

\section{INTRODUCTION}

Assume that $\mathrm{y}_{1}, \mathrm{y}_{2}, \ldots, \mathrm{y}_{\mathrm{g}}$ represent $\mathrm{g}$ independent binomial random variables. For ith group, $\mathrm{i}=1,2, \ldots, \mathrm{g}$, let $\mathrm{X}_{\mathrm{i} 1}, \mathrm{x}_{\mathrm{i} 2}, \ldots, \mathrm{X}_{\mathrm{ik}}$ denote the values on $\mathrm{k}$ explanatory variable which are thought to influence the individual trial probability of success, denoted by $\mathrm{P}_{\mathrm{i}}$. Then the linear logistic regression model is:

$$
\ln \left(\mathrm{P}_{\mathrm{i}} / \mathrm{Q}_{\mathrm{i}}\right)=\mathbf{x}_{\mathbf{i}}^{\prime} \beta \mathrm{i}=1,2, \ldots, \mathrm{g}
$$

where $\mathrm{Q}_{\mathrm{i}}=1-\mathrm{P}_{\mathrm{i}}$,

$$
\mathrm{x}_{\mathrm{i}}^{\prime}=\left(1, \mathrm{x}_{\mathrm{i} 1}, \ldots, \mathrm{x}_{\mathrm{ik}}\right) \text {, and } \beta^{\prime}=\left(\beta_{0}, \beta_{1}, \ldots, \beta_{\mathrm{k}}\right)
$$

The regression coefficients in $\beta$ are usually unknown and there are a number of well-known methods of estimation of $\beta$, such as maximum likelihood, minimum chi- square and weighted least squares.

Maximum likelihood: The maximum likelihood $(\mathrm{ML})^{[1-4]}$, is the most common method of estimation, since these estimates can now be routinely obtained by using many statistical packages such as GLIM, SHAZAM, MLOGIT, QUAIL, SAS PROC GENMOD and S-PLUS. Refer to ${ }^{[5-7]}$ for more details.

The kernel of the log-likelihood may be written a:

$$
L(\beta)=\sum_{i=1}^{g} n_{i}\left(p_{i} x_{i}^{\prime} \beta^{\prime}-\ln \left(1+e^{x_{i}^{\prime} \beta}\right)\right)
$$

where $p_{i}=y_{i} / n_{i}$ denotes the observed proportion of successes in the $\mathrm{i}^{\text {th }}$ group. In a matrix form the first and second order derivatives of the log- likelihood are given by:

$$
\frac{\partial L(\beta)}{\partial(\beta)}=\left(\begin{array}{l}
\sum_{\mathrm{i}=1}^{\mathrm{g}} \mathrm{n}_{\mathrm{i}} \mathrm{x}_{\mathrm{i} 1}\left(\mathrm{p}_{\mathrm{i}}-\mathrm{P}_{\mathrm{i}}\right) \\
\sum_{\mathrm{i}=1}^{\mathrm{g}} \mathrm{n}_{\mathrm{i}} \mathrm{x}_{\mathrm{i} 2}\left(\mathrm{p}_{\mathrm{i}}-\mathrm{P}_{\mathrm{i}}\right) \\
\vdots \\
\sum_{\mathrm{i}=1}^{\mathrm{g}} \mathrm{n}_{\mathrm{i}} \mathrm{x}_{\mathrm{ik}}\left(\mathrm{p}_{\mathrm{i}}-\mathrm{P}_{\mathrm{i}}\right)
\end{array}\right)
$$

and

$$
\frac{\partial^{2} \mathrm{~L}(\beta)}{\partial(\beta) \partial\left(\beta^{\prime}\right)}=-\mathrm{X}^{\prime} \mathrm{V}_{1} \mathrm{X}
$$

where $\mathrm{v} 1=\operatorname{diag}\left(\left(\mathrm{n}_{\mathrm{i}} \mathrm{P}_{\mathrm{i}} \mathrm{Q}_{\mathrm{i}}\right)\right)$ is a $(\mathrm{g} \times \mathrm{g})$ diagonal matrix and $\mathrm{X}$ is the $\left(\mathrm{g} \times(\mathrm{k}+1)\right.$ design matrix ${ }^{[2]}$. If we let $\hat{\beta}_{1}$ denote the $\mathrm{ML}$ estimate of $\beta$ and put $\mathrm{D}_{1}=\left(\frac{\partial \mathrm{L}(\beta)}{\partial \beta}\right)_{\beta=\bar{\beta}_{1}}, \hat{\mathrm{V}}_{1}=\left(\mathrm{V}_{1}\right)_{\beta=\bar{\beta}_{1}}$, then $\hat{\beta}_{1}$ is given by the solution of the $(\mathrm{k}+1)$ equations given by $\mathrm{D}_{1}=0$.

Applying a standard Newton-Raphson approach ${ }^{[8]}$ to solve these equations, if $\widehat{\beta}_{1}^{(\ell)}$ denotes the approximation to $\widehat{\beta}_{1}$ at the lth stage of iteration we have:

$$
\widehat{\beta}_{1}^{(\ell+1)}=\widehat{\beta}_{1}^{(\ell)}+\left(\mathrm{X}^{\prime} \widehat{\mathrm{V}}_{1}^{(\ell)} \mathrm{X}\right)^{-1} \mathrm{D}_{1}^{(\ell)}
$$

Corresponding Author: Hilmi F. Kittani, Department of Mathematics, Hashemite University, PO Box 150459, Zarqa13115 Zarqa, Jordan 
where $\hat{\mathrm{V}}_{1}^{(\ell)}$ and $\mathrm{D}_{1}^{(\ell)}$ denotes $\hat{\mathrm{V}}_{1}$ and $\mathrm{D}_{1}$ evaluated at $\widehat{\beta}_{1}^{(\ell)}$. The procedure is to calculate the estimates from a linear probability model and to use these as an initial values which begins finding a solution. When the difference between $\widehat{\beta}_{1}^{(\ell+1)}$ and $\widehat{\beta}_{1}^{(\ell)}$ is close enough to zero, the process stops. This iteration procedure may be viewed as a method of reweighted least squares.

Minimum chi- squares: The minimum chi- square (MCS) estimator ${ }^{[2,4]}$ which we denote by $\widehat{\beta}_{2}$ is the value of $\beta$ that minimizes:

$$
R(\beta)=\sum_{i=1}^{g} \frac{n_{i}\left(p_{i}-P_{i}\right)^{2}}{P_{i} Q_{i}}
$$

Writing

$$
\begin{aligned}
& R(\beta)=\sum_{i=1}^{g} n_{i}\left(p_{i}^{2} \frac{Q_{i}}{P_{i}}+q_{i}^{2} \frac{P_{i}}{Q_{i}}-2 p_{i} q_{i}\right) \\
& \sum_{i=1}^{g} n_{i}\left(p_{i}^{2} e^{-x_{i}^{\prime} \beta}+q_{i}^{2} e^{x_{i}^{\prime} \beta}-2 p_{i} q_{i}\right)
\end{aligned}
$$

The first and the second order derivatives of $\mathrm{R}(\beta)$ are:

$$
\begin{aligned}
& \frac{\partial \mathrm{R}(\beta)}{\partial \beta}=\left(\begin{array}{l}
\sum \mathrm{n}_{\mathrm{i}} \mathrm{x}_{\mathrm{i} 0}\left(\mathrm{q}_{\mathrm{i}}^{2} \frac{\mathrm{P}_{\mathrm{i}}}{\mathrm{Q}_{\mathrm{i}}}-\mathrm{p}_{\mathrm{i}}^{2} \frac{\mathrm{Q}_{\mathrm{i}}}{\mathrm{P}_{\mathrm{i}}}\right) \\
\sum \mathrm{n}_{\mathrm{i}} \mathrm{x}_{\mathrm{il}}\left(\mathrm{q}_{\mathrm{i}}^{2} \frac{\mathrm{P}_{\mathrm{i}}}{\mathrm{Q}_{\mathrm{i}}}-\mathrm{p}_{\mathrm{i}}^{2} \frac{\mathrm{Q}_{\mathrm{i}}}{\mathrm{P}_{\mathrm{i}}}\right) \\
\vdots \\
\sum \mathrm{n}_{\mathrm{i}} \mathrm{x}_{\mathrm{ik}}\left(\mathrm{q}_{\mathrm{i}}^{2} \frac{\mathrm{P}_{\mathrm{i}}}{\mathrm{Q}_{\mathrm{i}}}-\mathrm{p}_{\mathrm{i}}^{2} \frac{\mathrm{Q}_{\mathrm{i}}}{\mathrm{P}_{\mathrm{i}}}\right)
\end{array}\right) \\
& \frac{\partial^{2} \mathrm{R}(\beta)}{\partial \beta \partial \beta^{\prime}}=\mathrm{X}^{\prime} \mathrm{V}_{2} \mathrm{X}
\end{aligned}
$$

Where;

$$
\mathrm{V}_{2}=\operatorname{diag}\left(\left(\mathrm{n}_{\mathrm{i}}\left(\mathrm{p}_{\mathrm{i}}^{2} \frac{\mathrm{Q}_{\mathrm{i}}}{\mathrm{P}_{\mathrm{i}}}-\mathrm{q}_{\mathrm{i}}^{2} \frac{\mathrm{P}_{\mathrm{i}}}{\mathrm{Q}_{\mathrm{i}}}\right)\right)\right.
$$

Then $\widehat{\beta}_{2}$ is given by the solution of the $(k+1)$ equations given by:

$$
\mathrm{D}_{2}=0
$$

An iterative solution can again be found by using Newton- Raphson approach similar to that outlined for the maximum likelihood estimation procedure.
Weighted least squares: The ML and MCS estimation methods both require an iteration method of solution, although as we have noted the estimates can be obtained using many packages (straight forward). A none iterative solution can be found by using weighted least squares (WLS), which is sometimes referred to as minimum logit chi- square estimation ${ }^{[9]}$. Defining the group empirical logits by:

$$
z_{i}=\ln \left(\frac{p_{i}}{q_{i}}\right), i=1,2, \ldots, g
$$

we have,

$$
E\left(z_{i}\right)=x_{i}^{\prime} \beta+o\left(n_{i}^{-1}\right)
$$

and

$$
\mathrm{v}\left(\mathrm{z}_{\mathrm{i}}\right)=\left(\mathrm{n}_{\mathrm{i}} \mathrm{P}_{\mathrm{i}} \mathrm{Q}_{\mathrm{i}}\right)^{-1}+\mathrm{o}\left(\mathrm{n}_{\mathrm{i}}^{-2}\right)
$$

The WLS estimate is the value of $\beta$ which minimizes:

$$
\begin{aligned}
& S(\beta)=\sum_{i=1}^{g} n_{i} p_{i} q_{i}\left(\ln \frac{p_{i}}{q_{i}}-\ln \frac{P_{i}}{Q_{i}}\right)^{2} \\
& \sum_{i=1}^{g} w_{i}\left(z_{i}-x_{i}^{\prime} \beta\right)^{2}
\end{aligned}
$$

The weights $\mathrm{w}_{\mathrm{i}}=\mathrm{n}_{\mathrm{i}} \mathrm{p}_{\mathrm{i}} \mathrm{q}_{\mathrm{i}}$ are the reciprocal of the asymptotic variances of the $z_{i}$ 's based on the sample proportions of successes. Denoting the WLS estimate by $\widehat{\beta}_{3}$, the explicit solution is:

$$
\widehat{\beta}_{3}=\left(X^{\prime} \mathrm{WX}\right)^{-1} \mathrm{X}^{\prime} \mathrm{Wz}
$$

where $\mathbf{z}^{\prime}=\left(\mathrm{z}_{1}, \mathrm{z}_{2}, \ldots, \mathrm{z}_{\mathrm{g}}\right)$ and $\mathrm{W}=\operatorname{diag}\left(\left(\mathrm{w}_{\mathrm{i}}\right)\right)$.

The WLS method can be applied even if $p=0$ or 1 but because $z_{i}$ is itself undefined for these extreme cases therefore samples with $y_{i}=0$ or $n_{i}$ should be exempted when the estimation of $\widehat{\beta}_{3}$ is considered.

We use $\hat{\beta}$ to denote any estimator from the set $\widehat{\beta}_{1}, \widehat{\beta}_{2}, \widehat{\beta}_{3}$. It follows that the three estimators all have the same asymptotic properties with $\mathrm{E}(\widehat{\beta})=\beta$ and:

$$
\operatorname{COV}(\widehat{\beta})=\left(\mathrm{X}^{\prime} \mathrm{V}_{1} \mathrm{X}\right)^{-1}
$$


In the results of a fairly large scale simulation investigation that compare the moment properties of the estimators for a number of sample sizes and parameter configurations when we consider a single explanatory variable. These results considerably extend the findings made by ${ }^{[10]}$ who considered the particular case $g=3, n_{i}$ $=1,2,3$ and showed that the simple WLS method was more efficient than the ML and MCS methods of estimation under a number of success probability configurations.

Numerical results with discussions: In order to investigate the properties of the ML, MCS an WLS estimators, a large scale simulation was made for the case of a single explanatory variable with equally spaced values. Without loss of generality, the linear logistic regression model was taken as:

$$
\operatorname{Ln}\left(\mathrm{P}_{\mathrm{i}} / \mathrm{Q}_{\mathrm{i}}\right)=\beta_{0}+\beta_{1}(\mathrm{i}-1), \mathrm{i}=1,2, \ldots, \mathrm{g}
$$

Group numbers $\mathrm{g}=5,10$ and sample sizes $\mathrm{n}=25$, 50,100 were used, the simulation run size being, 1000 in each case. Three pairs of values $\left(\beta_{0}, \beta_{1}\right)$ were examined for each value of $g$ to give coverage of markedly different configurations for the groups trial probabilities of success, as shown in Table 1.

For the model given by Eq. 21, the elements in the information matrix are:

$$
\operatorname{Ln}\left(\mathrm{P}_{\mathrm{i}} / \mathrm{Q}_{\mathrm{i}}\right)=\beta_{0}+\beta_{1}(\mathrm{i}-1), \mathrm{i}=1,2, \ldots, \mathrm{g}
$$

where, $x_{i}=i-1$ The asymptotic variances and covariances for each of the three estimators are given by:

$$
\begin{aligned}
& \operatorname{var}\left(\hat{\beta}_{0}\right)=I_{22 / D}, \operatorname{var}\left(\hat{\beta}_{1}\right)=I_{11} / D, \\
& \operatorname{cov}\left(\hat{\beta}_{0}, \widehat{\beta}_{1}\right)=-I_{12} / D
\end{aligned}
$$

where $\mathrm{D}=\mathrm{I}_{11} \mathrm{I}_{22}-\mathrm{I}_{12}^{2}$.

In Table 2 , the variances of the estimators of $\beta_{0}$ and $\beta_{1}$ as obtained by simulation are given together with the approximate values given by 23 . The results show that the ML estimators gave the largest variances for both $\beta_{0}$ and $\beta_{1}$ in all cases. The variance differences for the MCS and WLS estimators were generally extremely small. The results also show that approximation 23 which is applicable to all the estimators gave satisfactory results especially when $n=100$.
Table 3 gives the means square errors of the estimators and the efficiencies of the MCS and WLS estimators relative to $\mathrm{ML}$ estimator defined as the ratio of the mean square errors. These efficiency results

\begin{tabular}{|c|c|c|c|}
\hline & $\beta_{0}$ & $\beta_{1}$ & $\left\{\mathrm{P}_{\mathrm{i}}\right\}$ \\
\hline $\mathrm{g}=5$ & & & \\
\hline (i) & -2.0 & 0.4 & $\begin{array}{lllll}0.119 & 0.168 & 0.232 & 0.310 & 0.401\end{array}$ \\
\hline (ii) & -1.0 & 0.5 & $\begin{array}{llllll}0.269 & 0.378 & 0.500 & 0.623 & 0.731\end{array}$ \\
\hline (iii) & 0.5 & 0.5 & $\begin{array}{lllll}0.623 & 0.731 & 0.818 & 0.881 & 0.924\end{array}$ \\
\hline $\begin{array}{l}\mathbf{g}=\mathbf{1 0} \\
\text { (iv) }\end{array}$ & -2.0 & 2.0 & $\begin{array}{l}0.1190 .1420 .1680 .1980 .2310 .2690 .310 \\
0.3540 .4010 .450\end{array}$ \\
\hline (v) & -0.4 & 0.2 & $\begin{array}{l}0.4010 .4500 .5000 .5500 .5910 .6460 .690 \\
0.7310 .7690 .802\end{array}$ \\
\hline (vi) & 0.5 & 0.2 & $\begin{array}{llll}0.623 & 0.668 & 0.7110 .750 & 0.7850 .8180 .846 \\
0.870 & 0.891 & 0.908\end{array}$ \\
\hline
\end{tabular}
suggest that the ML estimation procedure should not be

Table 1: Parameter values $\left(\beta_{0}, \beta_{1}\right)$ and group trial probabilities of

\begin{tabular}{|c|c|c|c|c|c|}
\hline \multicolumn{2}{|c|}{ Configuration } & ML & MCS & WLS & Approx (23) \\
\hline \multicolumn{6}{|c|}{ a) $\beta_{0}$} \\
\hline & (i) & 0.2118 & 0.1848 & 0.1768 & 0.1889 \\
\hline & (ii) & 0.1143 & 0.1083 & 0.1070 & 0.1143 \\
\hline \multirow[t]{6}{*}{$n=25$} & (iii) & 0.1272 & 0.1187 & 0.1190 & 0.1176 \\
\hline & (iv) & 0.1127 & 0.0998 & 0.0983 & 0.1018 \\
\hline & (v) & 0.0603 & 0.0560 & 0.0552 & 0.0586 \\
\hline & (vi) & 0.0661 & 0.0617 & 0.0620 & 0.0688 \\
\hline & (i) & 0.1017 & 0.0957 & 0.0940 & 0.0944 \\
\hline & (ii) & 0.0597 & 0.0581 & 0.0579 & 0.0571 \\
\hline \multirow[t]{6}{*}{$\mathrm{n}=50$} & (iii) & 0.0627 & 0.0607 & 0.0605 & 0.0588 \\
\hline & (iv) & 0.0538 & 0.0513 & 0.0510 & 0.0509 \\
\hline & (v) & 0.0282 & 0.0273 & 0.0273 & 0.0293 \\
\hline & (vi) & 0.0383 & 0.0372 & 0.0370 & 0.0344 \\
\hline & (i) & 0.0480 & 0.0464 & 0.0459 & 0.0472 \\
\hline & (ii) & 0.0301 & 0.0297 & 0.0296 & 0.0286 \\
\hline \multirow[t]{4}{*}{$\mathrm{n}=100$} & (iii) & 0.0319 & 0.0316 & 0.0315 & 0.0294 \\
\hline & (iv) & 0.0270 & 0.0264 & 0.0264 & 0.0255 \\
\hline & (v) & 0.0141 & 0.0139 & 0.0139 & 0.0146 \\
\hline & (vi) & 0.0174 & 0.0172 & 0.0172 & 0.0172 \\
\hline \multicolumn{6}{|c|}{ b) $\beta_{1}\left(\operatorname{var}\right.$ iances $\left.\times 10^{2}\right)$} \\
\hline & (i) & 2.5560 & 2.2950 & 2.2240 & 2.5013 \\
\hline & (ii) & 1.8980 & 1.7930 & 1.7740 & 1.9580 \\
\hline \multirow[t]{6}{*}{$\mathrm{n}=25$} & (iii) & 3.7530 & 3.1790 & 3.2030 & 3.1078 \\
\hline & (iv) & 0.3037 & 0.2721 & 0.2668 & 0.2903 \\
\hline & (v) & 0.2476 & 0.2278 & 0.2234 & 0.2360 \\
\hline & (vi) & 0.3098 & 0.2758 & 0.2761 & 0.3386 \\
\hline & (i) & 1.3770 & 1.3120 & 1.2900 & 1.2506 \\
\hline & (ii) & 1.0670 & 1.0370 & 1.0320 & 0.9790 \\
\hline \multirow[t]{6}{*}{$\mathrm{n}=50$} & (iii) & 1.6980 & 1.6020 & 1.5880 & 1.5539 \\
\hline & (iv) & 0.1548 & 0.1491 & 0.1486 & 0.1451 \\
\hline & (v) & 0.1197 & 0.1144 & 0.1138 & 0.1180 \\
\hline & (vi) & 0.1804 & 0.1718 & 0.1700 & 0.1693 \\
\hline & (i) & 0.5923 & 0.5762 & 0.5711 & 0.6253 \\
\hline & (ii) & 0.4945 & 0.4874 & 0.4863 & 0.4895 \\
\hline \multirow[t]{4}{*}{$\mathrm{n}=100$} & (iii) & 0.8168 & 0.7977 & 0.7942 & 0.7770 \\
\hline & (iv) & 0.0750 & 0.0740 & 0.0739 & 0.0726 \\
\hline & (v) & 0.0593 & 0.0585 & 0.0583 & 0.0590 \\
\hline & (vi) & 0.0865 & 0.0854 & 0.0849 & 0.0846 \\
\hline
\end{tabular}
success $\left\{\mathrm{P}_{\mathrm{i}}\right\}$ used in the simulation investigation

Table 2: Variances of estimators for configurations shown in Table 1 
used when the groups sample sizes are less than 100 . The efficiency differences between the MCS and WLS procedures are consistently small and WLS has the computational advantage of providing a non-iterative fit.

Table 3: Mean square errors and percentage efficiencies of estimators relative to the ML estimators for configurations shown in Table 1

\begin{tabular}{|c|c|c|c|c|c|c|}
\hline \multicolumn{2}{|c|}{ Configuration } & \multicolumn{2}{|c|}{ Mean square errors } & \multicolumn{3}{|c|}{ Efficiencies } \\
\hline \multicolumn{7}{|c|}{ a) $\beta_{0}$} \\
\hline & ML & MCS & WLS & MCS & WLS & \\
\hline & (i) & 0.2205 & 0.1851 & 0.1772 & 119.1 & 124.4 \\
\hline & (ii) & 0.1161 & 0.1087 & 0.1072 & 106.8 & 108.3 \\
\hline \multirow[t]{6}{*}{$\mathrm{n}=25$} & (iii) & 0.1277 & 0.1190 & 0.1197 & 107.3 & 106.7 \\
\hline & (iv) & 0.1135 & 0.1043 & 0.1079 & 108.8 & 105.2 \\
\hline & (v) & 0.0604 & 0.0560 & 0.0552 & 107.9 & 109.5 \\
\hline & (vi) & 0.0661 & 0.0618 & 0.0620 & 107.0 & 106.6 \\
\hline & (i) & 0.1027 & 0.0957 & 0.0942 & 107.3 & 109.0 \\
\hline & (ii) & 0.0597 & 0.0582 & 0.0580 & 102.6 & 102.9 \\
\hline \multirow[t]{6}{*}{$\mathrm{n}=50$} & (iii) & 0.0627 & 0.0607 & 0.0605 & 103.3 & 103.6 \\
\hline & (iv) & 0.0538 & 0.0531 & 0.0536 & 101.3 & 100.4 \\
\hline & (v) & 0.0284 & 0.0273 & 0.0273 & 104.0 & 104.0 \\
\hline & (vi) & 0.0383 & 0.0372 & 0.0371 & 103.0 & 103.2 \\
\hline & (i) & 0.0482 & 0.0464 & 0.0460 & 103.9 & 104.8 \\
\hline & (ii) & 0.0302 & 0.0297 & 0.0296 & 101.7 & 102.0 \\
\hline \multirow[t]{4}{*}{$\mathrm{n}=100$} & (iii) & 0.0319 & 0.0316 & 0.0315 & 101.0 & 101.3 \\
\hline & (iv) & 0.0270 & 0.0269 & 0.0270 & 100.4 & 100.0 \\
\hline & (v) & 0.0141 & 0.0139 & 0.0137 & 101.4 & 101.4 \\
\hline & (vi) & 0.0174 & 0.0172 & 0.0172 & 101.2 & 101.2 \\
\hline \multicolumn{7}{|c|}{ b) $\beta_{1}\left(\right.$ mean square errors $\left.\times 10^{2}\right)$} \\
\hline & (i) & 2.6311 & 2.3040 & 2.2240 & 114.2 & 118.3 \\
\hline & (ii) & 1.9311 & 1.7970 & 1.7752 & 107.5 & 108.8 \\
\hline \multirow[t]{6}{*}{$\mathrm{n}=25$} & (iii) & 3.7684 & 3.2160 & 3.3745 & 117.2 & 111.7 \\
\hline & (iv) & 0.3051 & 0.2767 & 0.2783 & 110.3 & 109.6 \\
\hline & (v) & 0.2491 & 0.2288 & 0.2255 & 108.9 & 110.5 \\
\hline & (vi) & 0.3099 & 0.2897 & 0.3099 & 107.0 & 100.0 \\
\hline & (i) & 1.3879 & 1.3120 & 1.2900 & 105.8 & 107.6 \\
\hline & (ii) & 1.0689 & 1.0370 & 1.0323 & 103.1 & 103.6 \\
\hline \multirow[t]{6}{*}{$\mathrm{n}=50$} & (iii) & 1.7040 & 1.6060 & 1.6028 & 106.1 & 106.3 \\
\hline & (iv) & 0.1548 & 0.1512 & 0.1518 & 102.4 & 102.0 \\
\hline & (v) & 0.1205 & 0.1144 & 0.1140 & 105.3 & 105.7 \\
\hline & (vi) & 0.1805 & 0.1744 & 0.1749 & 103.5 & 103.2 \\
\hline & (i) & 0.5936 & 0.5762 & 0.5713 & 103.0 & 103.9 \\
\hline & (ii) & 0.4951 & 0.4875 & 0.4863 & 101.6 & 101.8 \\
\hline \multirow[t]{4}{*}{$\mathrm{n}=100$} & (iii) & 0.8265 & 0.7986 & 0.7944 & 103.5 & 104.0 \\
\hline & (iv) & 0.0750 & 0.0746 & 0.0746 & 100.5 & 100.5 \\
\hline & (v) & 0.0593 & 0.0588 & 0.0587 & 100.9 & 101.0 \\
\hline & (vi) & 0.0867 & 0.0856 & 0.0852 & 101.3 & 101.8 \\
\hline
\end{tabular}

\section{REFERENCES}

1. Montgomery D.C., Peck, E.A. and Vining, G. G. (2001). Introduction to Linear Regression Analysis, $3^{\text {rd }}$ ed., Wiley, New York, , pp.193-196. ISBN 0-471-31565-6

2. Berkson, J. (1995). Maximum likelihood and minimum Chi-square estimates of the logistic function, J. Amer. Statist. Assoc., Vol. 50, pp. 130162.links.jstor.org/sici?sici=0006341X(198509)41\%3A3\%3C777\%3AMLVMC\%3E2.0.C O\%3B2-W

3. Verbeek, M. (2000). A guide to modern Econometrics, $3^{\text {rd }}$ ed. Wiley, New York, pp.152-174. ISBN: 978-0-47051769-7

4. Hogg, R.V. and Craig, A. T. (1995). Introduction To Mathematical Statistics, $5^{\text {th }}$ ed., Prentice Hall, New Jersey, pp.261-266 \& 298-299.

ISBN-10: 0023557222

5. Baker, R.J. and Nelder, J.A. (1978). Generalized Linear Interactive Modeling (GLIM), Numerical Algorithms Group, Journal of the American Statistical Association, Vol. 74, No. 368 (Dec., 1979), pp. 934-935.

http://www.jstor.org/action/showPublisher?publisherCod $\mathrm{e}=$ astata

6. Amemiya, T. Qualitative Response Model (1981): A Survey, J. of Economic Literature. Vol.19, pp. 14881536.http://www.jstor.org/fcgibin/jstor/listjournal.fcg/00220515/.11-.20

7. SAS Institute (1994): Principles of Regression Analysis Course Notes, SAS Institute Publishing company, Cary, N.C.ISBN-10: 1555446043

8. Burden, R L. and Faires, J. D. (2001). Numerical Analysis, $7^{\text {th }}$ ed., Wadsworth Group, pp. 66-72. ISBN-10: 0534382169

9. Johnson, R. A. and Wichern, D., W. (1998). Applied multivariate statistical analysis. $4^{\text {th }}$ ed., Prentice Hall, New Jersey, (1998), pp.187-183, $448 . \quad$ ISBN 0-13834194-x

10. Johnston, J. and Dinardo, J. (1997). Econometric Methods, $4^{\text {th }}$ ed., McGraw-Hill, New York, pp.342343,433-434. ISBN: 0070327203 